Student Success

ISSN: 2205-0795

Volume 9, Issue 1, pp. 35-46

February 2018

\title{
Exploring students' uses of and dispositions towards learning technologies in an Australian enabling course
}

\author{
Rhian Morgan
}

James Cook University, Townsville, Australia

\section{Abstract*}

University progression is increasingly dependent upon students developing a range of digital literacies in conjunction with the skills associated with their disciplines. University enabling and pathway programs, in particular, have a key part to play in supporting students to interact with technologies for learning. Widening participation and increased student diversity result in highly variable levels of digital literacy in the classroom. As such, universities need to develop strategies to effectively respond to the differing abilities of students entering the sector. This paper contributes to the development of such responses through a case study exploring students' use of and dispositions towards technologies in an open access enabling course. In this context 'open access' refers to the course admission requirements and the fact that the course enrollments are open to anyone over the age of eighteen, regardless of their prior schooling experience. The paper identifies trends in students' uses of technology, such as preferences for mobile content and blended learning environments, before concluding with a discussion of how these findings can be mobilised in curriculum development.

*This article was first presented at the National Association of Enabling Educators of Australia Conference, Gold Coast, Australia in December 2017 and was selected via the peer review process as one of the top-rated papers. The author has kindly given their permission to have this article published in this special issue of the Journal and it has undergone a further review by the guest editors to confirm it aligns with the Journal standards.

Please cite this article as:

Morgan, R. (2018). Exploring students' uses of and dispositions towards learning technologies in an Australian enabling course. Student Success, 9(1), 35-46. doi: 10.5204/ssj.v9i1.431

This article has been accepted for publication in Student Success. Please see the Editorial Policies under the 'About' section of the Journal website for further information.

Student Success: A journal exploring the experiences of students in tertiary education

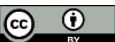

This work is licensed under a Creative Commons Attribution 4.0 International Licence. As an open access journal, articles are free to use, with proper attribution, in educational and other non-commercial settings. ISSN: 2205-0795 


\section{Introduction}

We live in a world of rapid economic and technological change. Digital technologies permeate every aspect of our lives, affecting how we communicate, find and provide information, build relationships, trade and purchase goods and, critically, how we learn and teach

(Jisc, 2012, p.5).

The ubiquity of web 2.0 technologies means that university progression is increasingly dependent on students developing a range of digital literacies ${ }^{1}$ in conjunction with the specialist skills associated with their disciplines. Universities in general, and enabling programs $^{2}$ in particular, have a key part to play in supporting students to interact with technologies for learning. Digital literacy skills allow students to take advantage of flexible and distance learning opportunities (Yang, Catterall \& Davis, 2013). However, in an era of widening participation it is necessary to heed the cautions expressed by the Educating the Net Generation report (Kennedy et al., 2009) and be wary of the assumption that all students will enter the sector fully equipped to use their existing digital literacies to support their academic endeavours (Owens \& Lilly, 2017). Furthermore, while some students may be skilled technology users prior to their entry into higher education, many lack the specific digital competencies required to be successful in an academic context (Joint Information Systems Committee [Jisc], 2014). In particular, culturally and linguistically diverse (CALD) cohorts within Australian pathway programs have been shown to be underprepared in terms of the digital capabilities required for university study (Roche, 2017). As such, universities need to develop strategies to assess and effectively respond to the differing abilities of students entering the sector. This paper presents a case study exploring students' uses of and dispositions towards technologies in an open access enabling course, within an Australian regional university. The paper begins by outlining the international, national, and institutional contexts within which the study is situated, before moving on to describe the study's methods and key findings. The paper concludes with a discussion of how these findings can be used to help provide equitable digital literacies instruction that will adequately prepare all students for technology-rich study environments.

\section{International, national and institutional context}

This case study sits within the widening digital literacies in higher education agenda both internationally and nationally. Internationally, EDUCAUSE in the United States (US) have been instrumental in supporting the higher education sector to investigate students' digital literacies. For example, EDUCAUSE's annual "Students and IT" survey provides significant insight into the digital practices of students. For example, their 2015 survey gathered data from 50274 students, at 161 institutions, across 11 countries and some of the key findings were that:

- $\quad$ students' use of technology for academic purposes is broad (they use a wide range of technologies), but they may require assistance in using technologies efficiently and effectively for learning;

\footnotetext{
${ }^{1}$ In the context of this paper digital literacies are defined as the capabilities that support an individual to live, learn and work in a digital society (Jisc, 2011).

2 Enabling programs are sub-degree courses of study designed to prepare students for entry into standard Bachelor degree programs, they may or may not result in a distinct qualification, such a diploma (Pitman, et al., 2016).
} 
- although omnipresent in students' lives, processes of leveraging technology as an engagement tool are still evolving; and

- students have a complex relationship with technology - they recognise its value but still need guidance in order to use it in meaningful ways

(Dahlstrom, Brooks, Grajek \& Reeves, 2015).

The importance of institutional support and training for students in the effective use of learning technologies is acknowledged in benchmarks set by the New Media Consortium (Johnson, Becker \& Hall, 2015). In the higher education context of the United Kingdom, Jisc have been instrumental in bringing together a conceptual framework (Jisc, 2015) that describes the digital literacies necessary for student success. The six capabilities model of digital literacies (illustrated in figure 1) identifies the variety of digital literacies that higher education students need to master including: Information and communications technology (ICT) literacy; information, data, and media literacy; digital learning and selfdevelopment; and identity and well-being. In doing so, the Jisc framework identifies the foundational importance of ICT proficiency, while simultaneously acknowledging that a holistic understanding of digital literacy must attend to the collaborative, evaluative, and socio-emotional dimensions of technology use as well. In an Australian context the Educating the

Net

Generation report (Kennedy et al., 2009) paints a similarly complex picture of students' relationships with technologies. In preparing the report the authors conducted an "experiences with technology" questionnaire, coupled with qualitative data collection. Key findings from the questionnaire indicate that: there is little empirical support for the rhetoric that university students are more digitally proficient than staff; there is great diversity in student experiences with and preferences for the use of technology in higher education; and, the technological experiences first-year university students bring to higher education are highly varied (Kennedy et al, 2009, p. 3).

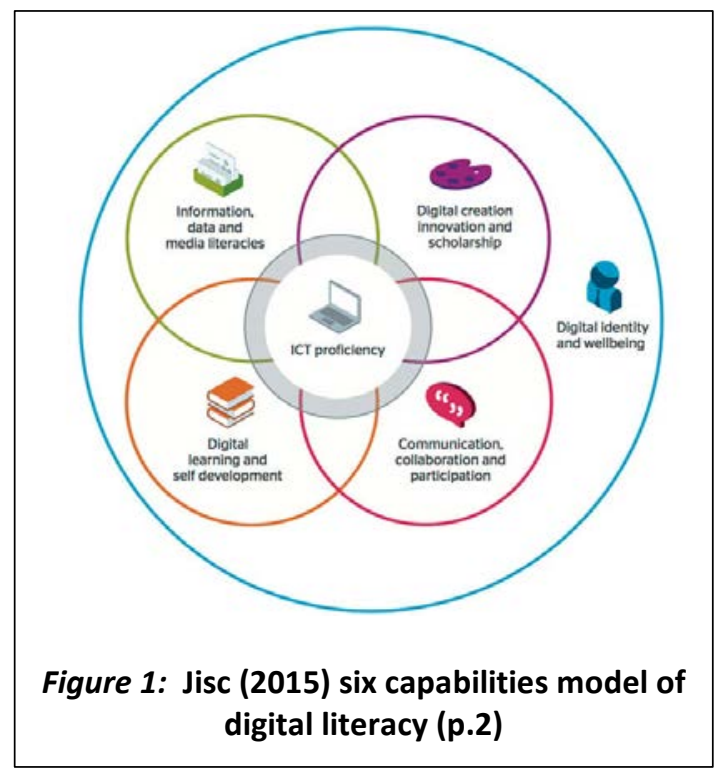

There are few specific studies of the digital literacies of students in Australian pathway and enabling education, with the notable exception of Roche's (2017) assessment of digital literacies instruction within an English for Academic Purposes (EAP) pathway course. Roche's analysis demonstrates that a focus on digital literacies within enabling curricula can assist culturally and linguistically diverse (CALD) students in adjusting to the academic requirements of university study. Broader studies of enabling and pathway programs have identified that students in these programs are more likely to belong to one or more identified equity groups than students enrolled in Bachelor' degrees (Pitman et al., 2016). In a review of Australian enabling and pathway courses, conducted for the National Centre for Student Equity in Higher Education (NCSEHE), Pitman et al. found that "approximately three out of every five students enrolled [in a pathway or sub-bachelor program] in 2014 had 
experienced at least one form of recognised educational disadvantage, compared to two out of five students at the undergraduate level" (p.33). The NCSEHE review also shows that pathway and enabling programs tend to attract large numbers of students from low socioeconomic backgrounds and students from regional or remote areas. Students belonging to recognised equity groups who complete an enabling course are more likely to be retained at Bachelor's level than those that do not. Furthermore, Boyle and Abdullah's (2015) survey of students' motivations for studying within enabling programs has identified skills development as a key motivating factor for students enrolling in pre-degree courses. Together with the insights provided by EDUCAUSE (Dahlstrom et al., 2015) and trends toward flexible and blended learning in the university sector, these national studies provide a clear imperative for digital literacies instruction in pre-degree education. In response to this need, James Cook University's (JCU) pathway program, the Diploma of Higher Education (DHE) requires all commencing students to complete a one semester digital literacies subject - named CS1022: Learning in a Digital Environment - as part of its core curriculum.

The DHE is a one year, open access, program that attracts a diverse array of students with highly variable educational backgrounds. For example, within CS1022 the 2016 cohort consisted of 751 students, spread across two semesters, and located at JCU's four main campuses in Townsville, Cairns, Singapore and Brisbane. Of these students:

- $14 \%$ were from low socioeconomic backgrounds

- $28 \%$ spoke English as an additional language

- $47 \%$ were the first in their families to attend university
- $11 \%$ identified as Australian Aboriginal and/or Torres Strait Islander students

- $10 \%$ identified as having a disability

- and 50\% had no OP (overall position) score or equivalent, meaning that they either did not complete high-school in Australia, or attended high-school prior to the implementation of the OP system.

CS1022 utilises a blended learning model, whereby weekly course videos and concept orientated websites complement on campus workshops and face-to-face learning support. This model enables students to build their knowledge outside the classroom, therefore freeing up class-time for active learning and the guided development of practical skills. However, in technology-rich university environments a lack of confidence and procedural knowledge in relation to ICT applications can hinder learning (Wecker, Kohnlet \& Fischer, 2007). Following an initial run through of CS1022 in 2015 it became apparent that further investigation into the technological practices of students would be necessary in order to develop resources that could sufficiently cater to such a diverse cohort. The 2014 iteration of the EDUCAUSE Students and IT survey (Dahlstrom \& Bichsel, 2014) was subsequently selected as the analytic basis for an investigation of the digital practices of students within JCU's Diploma of Higher Education.

\section{Methodology}

The study began with the development and testing of a JCU specific Students and IT Survey, based on the EDUCAUSE Centre for Analysis and Research (ECAR) Students and Technology Survey (Dahlstrom \& Bichsel, 2014). The adaptations of the survey consisted of the replacement of generic references to learning management systems with references to JCU specific platforms, the substitution of American terminology, such as 'freshman', with Australian 
terminology, and the removal of questions aimed at post-graduate students. Sections of the original ECAR survey were removed in the start of semester survey in order to facilitate a baseline measurement of digital practices among students with no prior university experience. These minor adaptations did not impact the construct validity of the survey, but simply rendered it comprehensible and relevant to an Australian audience of incoming diploma-level students with no prior university experience. Two sets of surveys were conducted among commencing CS1022 students in 2016, once when students began their studies (T1), in week 1, and again towards the end of semester (T2), in week 11 of a 13-week semester. In addition to collecting demographic information and data on students' intended course of study the surveys explored the following four dimensions of technology use:

- device use and ownership,

- technology and students' university experience,

- $\quad$ preferences and experiences of learning environments, and

- dispositions towards technology.

Device ownership was assessed through a series of five multiple choice questions that looked at the number and type of internet capable devices owned, the operating systems used, and home internet access. Device usage was assessed through three sets of questions, using a five-point rating scale; participants were asked to select how frequently they used specific devices for both academic purposes and other purposes and rate the importance of specific devices for their academic success and specific aspects of study, such as accessing grades, or viewing lecture recordings. Technology and university experience was assessed using a five point Likert scale. On a scale from 1 = strongly agree to 5 = strongly disagree students were asked to evaluate the extent to which they believed improvements in specific technology skills would impact how effective they were at studying. This dimension looked at 10 aspects of learning technologies, including: university specific platforms, such as the institutional learning management system (LMS); devices, such as laptops and smartphones; and, use of in-put devices, such as keyboards or touchscreens. Preferences for learning environments were assessed using ten statements, such as "I get more actively involved in subjects that use technology", and a six point Likert scale ( 1 = strongly agree, 3 = neutral, 5 = strongly disagree, 6 = don't know). Dispositions towards technologies were determined using three questions and a 10-point semantic scale. Participants were asked to rate themselves in terms of their levels of connectivity (from $1=$ never connected to 10 = always connected), their attitudes towards technology (from dissatisfied to satisfied), and their outlook towards technology (from scared to enthusiastic). In the end of semester survey, these questions were supplemented by two open-ended questions, asking students firstly, what their lecturers could do with technology to support their academic success and secondly, what the university could do with technology to support them. Survey responses were deidentified and collated using Microsoft Excel. Data from pre- and post surveys were then processed in Excel using descriptive statistics, primarily distributions and trends, which were analysed using Grounded Theory (Strauss \& Corbin, 1990). This approach follows an inductive process, by which the data is coded in accordance with emergent patterns in responses, from which themes may be identified. In accordance with Strauss and Corbin this analytic process is able to account for emergent trends in data and variations in 'fit' between survey findings and existing frameworks - such as the ECAR dataset (Dahlstrom et al., 2015). The findings outlined below are the result of subsequent analyses of survey data in comparison to findings of the ECAR study and other key literature. Findings on device ownership and usage are in a distinct 
subsection. Reporting on the remaining three dimensions is provided in a combined subsection, titled 'technologies and the student experience'.

\section{Results}

The pre-semester (T1) survey was deployed among an initial cohort of 435 students and received 417 responses (response rate 95\%). The end of semester (T2) survey was deployed among a cohort of 317 students and received 150 responses (response rate $47 \%$ ). The lower response rate for the T2 survey was partially the result of an overall cohort attrition rate of $27 \%$. The gender breakdown of respondents was fairly equal and age profiles were similar for both surveys, with most students (45-46\%) located within the 20-29 age bracket. Survey responses indicated preferences for mobile learning, in addition to revealing trends in students' attitudes towards technologies.

\section{Device use and ownership}

Rates of home internet access among participating students were similar to the national average, which stands at $90 \%$ (Australian Media \& Communications Authority [ACMA], 2016). In both T1 and T2 surveys $91 \%$ of students reported having internet access at home; however, in $6 \%$ of cases the students' only means of accessing the internet at home was via smartphone. Overall trends in device ownership among the DHE students were similar to the those reported in the preceding ECAR study (Dahlstrom et al., 2015), with smartphone ownership (89\%) slightly exceeding laptop ownership (87\%) at the start of semester. Rates of device ownership among DHE students at the start of semester were marginally lower than those reported in the ECAR study which stood at $92 \%$ for smartphones and 91\% for laptops (Dahlstrom et al., 2015).

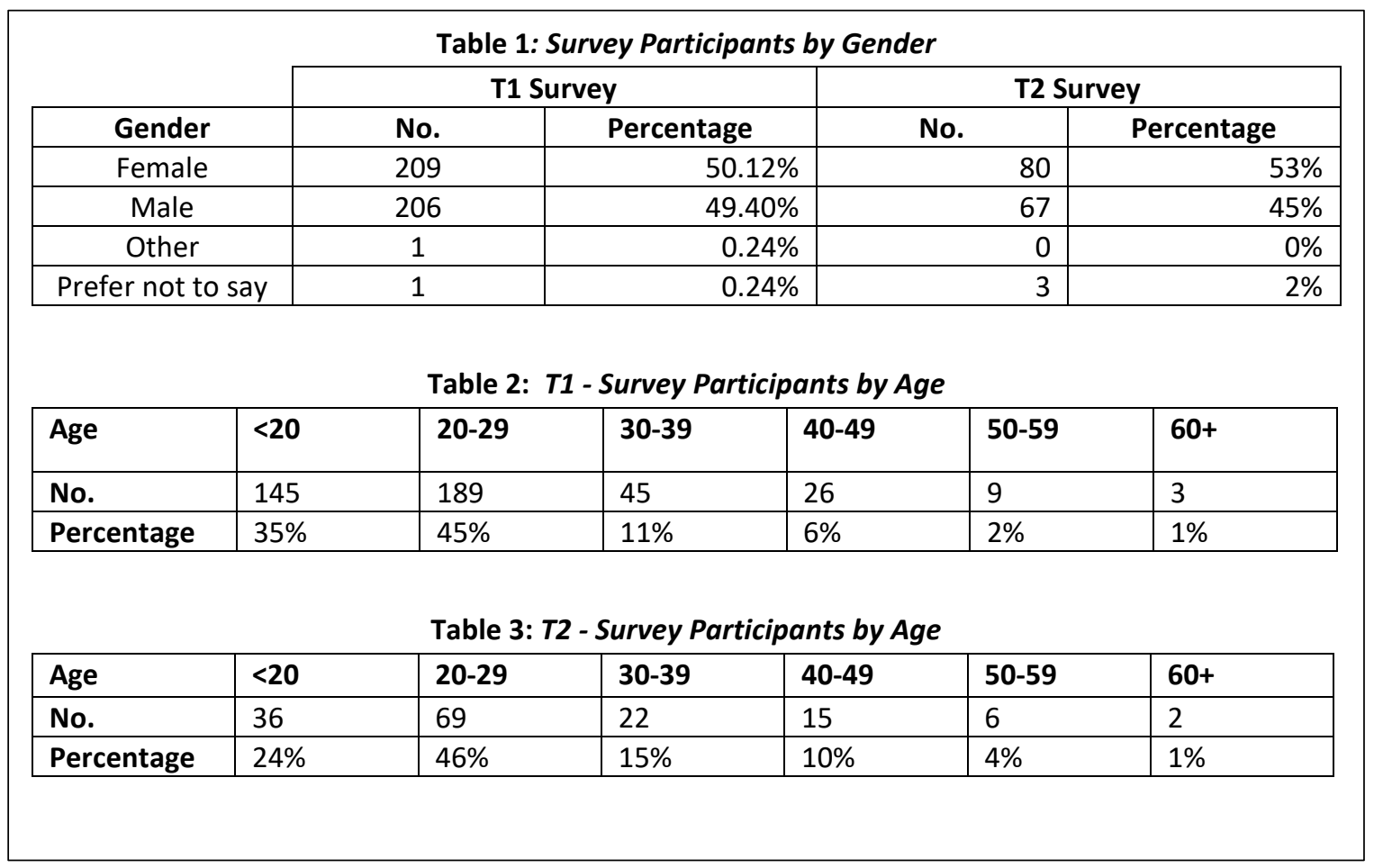


By the end of semester rates of device ownership among DHE students were comparable to those reported in ECAR. Smartphone ownership among DHE students was higher than the national average, which lies at $76 \%$ for Australian adults (ACMA, 2016). A comparable trend was identified in relation to US college students and the general American population. Tablet ownership was particularly low at the start of semester, with only $3 \%$ of DHE students owning a tablet in comparison to the $54 \%$ of students that reported owning a tablet in the ECAR study (Dahlstrom et al., 2015).

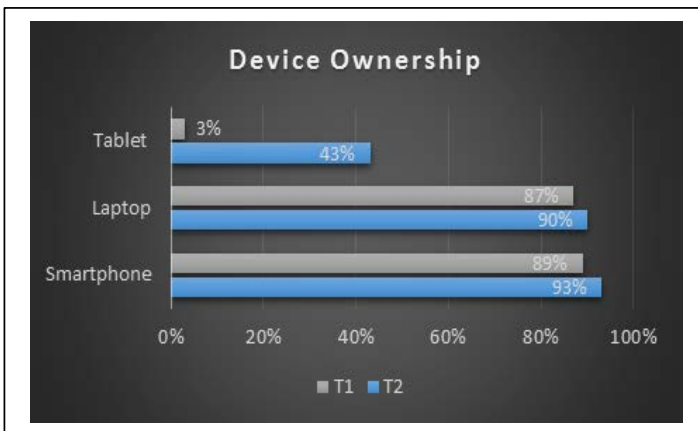

Figure 2: Trends in device ownership among DHE students

Rates of device ownership among DHE students increased over the semester for all categories of internet capable devices, with the greatest growth occurring in tablet ownership which increased from $3 \%$ to $43 \%$ among the participating cohort. This growth is likely due to the originally low rates of ownership, as the percentage of students who considered tablets moderately to extremely important to their academic success remain relatively constant across both surveys (T1:58\%, T2:57\%). Overall, students considered laptops the most important device for study. Perceptions regarding the relative importance of laptops for study shifted upwards slightly over the course of the semester, with $59 \%$ of students rating laptop ownership as extremely important to their academic success in the $\mathrm{T} 2$ survey, compared to $53 \%$ at the start. Survey results confirmed the importance of mobile devices for both practical and social dimensions of learning, with peer interactions (83\%) and accessing subject content via the learning management system (LMS) (82\%) emerging as the most important mobile learning activities.

DHE students tended to rank the importance of mobile devices for their learning more highly than the general student population surveyed in the ECAR study. In the ECAR study, checking grades is ranked as the most important mobile learning activity by just over $70 \%$ of students (Dahlstrom et al., 2015). Dahlstrom et al. did identify a particular preference for mobile learning among ECAR respondents from low SES backgrounds and first-generation students, which is attributed to higher rates of smartphone dependence among lower-income families. The large number of first-generation students in the DHE cohort is therefore a potential causal factor in relation to the high importance placed on smartphones as a primary learning tool.

\section{Technologies and the student experience}

Overall, the DHE students had a positive outlook towards technologies and reported high levels of connectedness. Technology was viewed as a key factor in engagement by a significant proportion of the cohort: $43.1 \%$ of students either agreed or strongly agreed with the statement "I get more actively involved in subjects that use technology" at the start of semester (only $10 \%$ of students disagreed with the statement, with $35.5 \%$ remaining neutral). These responses remained relatively stable across the semester with a slight increase in the number of students that reported getting more actively involved in subjects that use technology 


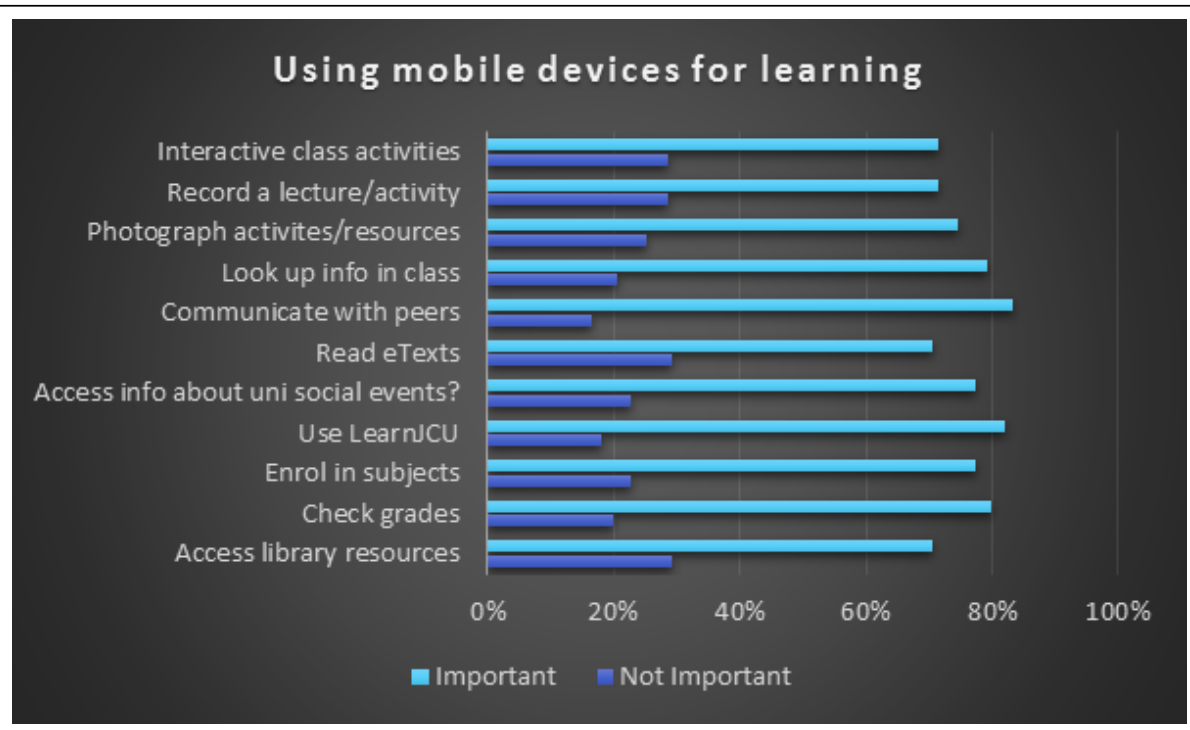

Figure 3: The relative important of accessing content via mobile devices

(47\%). These results are similar to the responses of the ECAR survey where $49 \%$ of students either agreed or strongly agreed with the above statement (Dahlstrom et al., 2015).

The majority of students (66\%) felt that they learned best in blended learning environments. Despite rhetoric surrounding digital natives and young students' preferences for technology enabled learning, preferences for blended learning environments were uniformly high across all age groups surveyed. The number of students that felt they learned best in completely online environments was low across all age groups (9-11\%) and a specific preference for blended learning was highest among 40-49 year olds (77\%) and 30-39 year olds (69\%). Only 6\% of students expressed a preference for purely face-to-face instruction. Preferences for purely face-to-face learning were highest among students under 20 (11\%) and 50-59 year olds $(11 \%)$. These age groups also reported the lowest levels of home internet access, with 14\% of students under 20 and $11 \%$ of 50-59 years olds stating that they did not have internet access at home. A preference for blended content delivery was also apparent in students' open-ended feedback.

In response to an open-ended question about how lecturers could use technologies to support students' academic success, 33\% of students expressed a desire for increased online access to class content, specifically recorded lectures or lecture slides. Provision of class materials online is increasingly becoming standard practice among JCU lecturers. Yet, the process of leveraging technologies as engagement and content delivery tools in this manner can be somewhat fraught, as faculty often perceive the online availability of resources as having a negative impact on attendance (Davis, Connolly, \& Linfield, 2009). However, empirical data indicates that the availability of lecture recordings does not negatively impact attendance and students value lecture recordings, not as substitutes for attendance, but as 'back-up' options and for revision purposes (White, 2009; Yeung, Raju \& Sharma, 2016). The responses provided by DHE students affirm these findings, as students' statements regarding online class materials 
were frequently motivated by a desire to engage in independent study:

- "Upload lecture recordings onto LearnJCU [Blackboard] for study purposes"

- "Record lectures and lecture slides so they are accessible at later a date"

- "Making the slides available before class to get an idea about what we will be learning and write down any questions we may have before the lecture to see if they are answered in the lecture or having to see the lecturer after class"

- "Record lectures, so students are able to go back over the material"

- $\quad$ "Record the lectures and tutes more so I can revisit and review the notes"

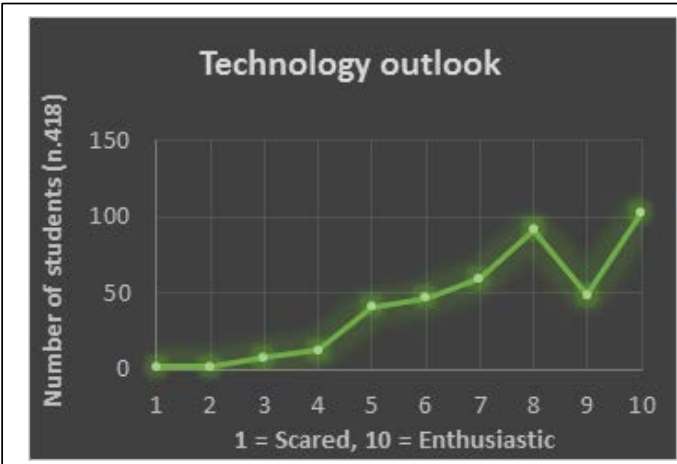

Figure 4: Students outlook towards

Of the students surveyed $51 \%$ stated that the availability of class materials online did not impact their attendance. Only $25 \%$ of students felt that the availability of online materials increased the likelihood of them skipping class, with $22 \%$ remaining neutral.

Students in this enabling program, and mature aged students in particular, valued the combination of flexibility and support that blended learning provides. However, despite an expressed preference for blended learning, a significant percentage of students stated that they felt underprepared in terms of their knowledge of basic software (45\%) and university systems (55\%) when they commenced their studies. These results contrast the findings of the ECAR survey in which $67 \%$ of students stated that they felt adequately prepared to use technologies when they started university (Dahlstrom, et al., 2015).

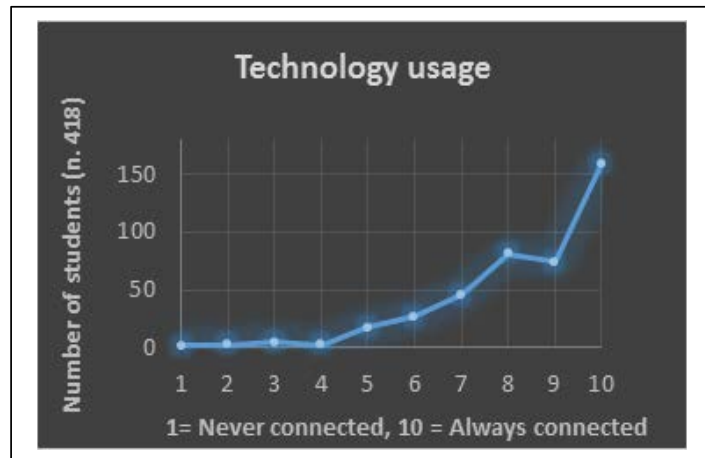

Figure 5: Students' degree of connectedness

This divergence from ECAR trends demonstrates that research on broader student populations will not necessarily capture the specificities of teaching in enabling and predegree spaces, particularly in relation to variables such as university preparedness and perceived self-efficacy. Self-efficacy is an important factor with respect to persistence and retention in STEM disciplines (MacPhee, Farro \& Canetto, 2013). In relation to digital technologies "higher self-perceived Internet skills ... [are] positively related with higher [actual] web-use skills" (Owens \& Lilly, 2017, p.300). However, students from lowsocioeconomic backgrounds have been shown to demonstrate lower levels of academic selfefficacy, meaning that they are more likely to evaluate their academic and technical skills as 'poor', regardless of their actual observable skill level (Rocchino, Dever, Telesford, \& Fletcher, 2017). Within enabling programs, the influence of demographic factors on self-efficacy and consequent impacts on students' confidence in 
using learning technologies needs to be taken into consideration with regards to both learning design and course evaluation.

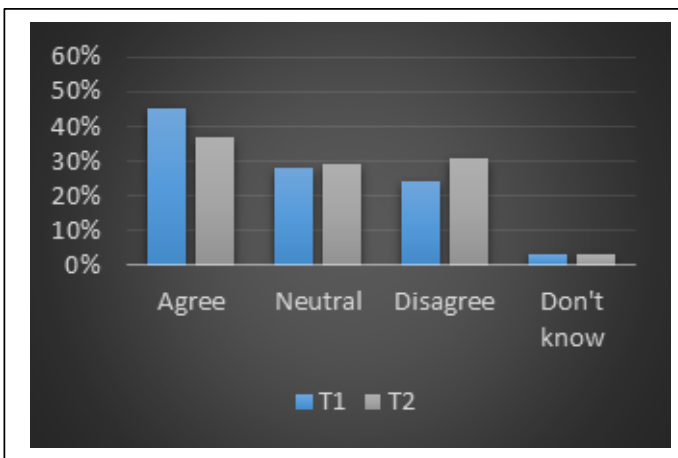

\section{Figure 6: I wish I had been better prepared to use basic software programs (Word, Excel, Outlook etc.)}

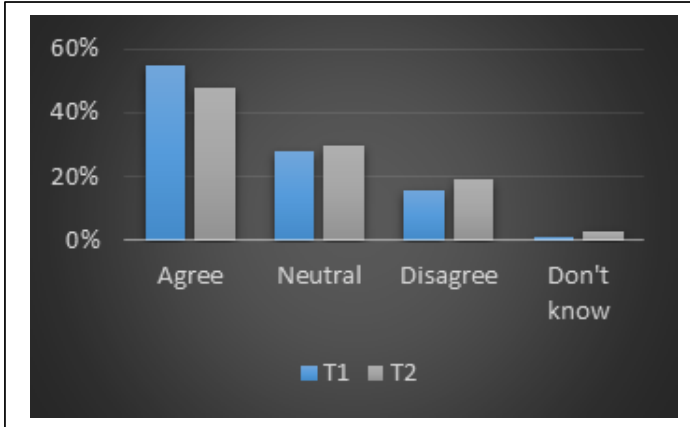

Figure 7: I wish I had been better prepared to use the university's systems (eStudent, LearnJCU, OneSearch)

\section{Discussion}

Authentic learning occurs when task design and the context in which learning occurs reflect processes of knowledge application in the 'realworld' (Herrington, Reeves \& Oliver, 2010). In the context of preparatory digital literacies instruction, authenticity in curriculum design is dependent on the orientation of content around the technologies and technical scenarios that students are likely to be confronted with during their tertiary studies. In addition, instructors and educational designers must remain mindful of the practical requirements of technology enabled study. Dahlstrom et al. (2015) argue that students expect technologies to be used as content delivery and engagement tools. Survey findings confirm the applicability of this statement to Australian pathway students, while also drawing attention to the necessity of supporting students' engagements with learning technologies. This support must be guided by trends in students' actual uses of and dispositions towards technologies and technology enabled learning.

Key themes in relation to DHE students' uses of technologies include: high rates of smartphone ownership and related tendencies to access subject content via mobile devices; the use of smartphones as a key tool for peer-engagement; a preference for blended content delivery; and a desire to have class content available online for revision purposes. Students reported high levels of connectedness and acknowledged the importance of technologies for university learning, while also recognising the need for guidance in relation to the use of software and university systems. Correlations between preferred learning environments and internet access demonstrate that students' dispositions towards blended learning are influenced by practical considerations, such as the ability to engage in off campus study. These trends in device ownership and considerations regarding equitable access to resources all need to be considered when developing digital content. Dahlstrom et al., (2015) state that higher education institutions are "in a unique position to leverage these devices as productivity tools, as assets for learning" and this statement is just as applicable to teaching and learning in Australian enabling courses as it is in US colleges (p.13). However, when implementing mobile learning solutions instructors must 
remain mindful of the challenges associated with mobile study, like reduced connectivity in regional areas (Schimer, Yabsley, Mylek, \& Peel, 2016) and the costs associated with accessing blended content, such as video, via mobile devices. Primacy should be placed on crossplatform compatibility and issues associated with mobile consumption, such as the bandwidth and data requirements, should be forefront during the learning design process (Adams Becker, et al., 2017). As such, the continued implementation of survey findings in CS1022 will involve adjustments of blended content to ensure mobile compatibility; for example, through the reduction of video length, provision of transcripts to all students, and hosting of videos on platforms that allow for adaptive streaming - where video quality dynamically adjusts to network conditions.

\section{Conclusions}

Learners need support in developing the transferable digital literacies required for success in university learning contexts. Context is fundamental to our understandings of the digital literacies required by commencing students and it is important to consider the diverse backgrounds of students in the development of instructional content to support learning in the digital learning environments common to contemporary higher education. In an Australian regional context, widening participation means catering to students from differing age groups and students of all genders, as well as students from varying socioeconomic and cultural backgrounds, and students with specific learning or accessibility needs. Varying levels of exposure to technology, and divergent prior work or school experiences, mean that these students exhibit highly variable levels of pre-existing technical competencies. Technologies can be mobilised as key methods of promoting engagement. However, instructors must consider the manner in which socio-economic factors and technological trends may influence people's dispositions towards and access to technologies. Rhetoric around digital natives is neither helpful, nor accurate, when it comes to preparing diverse student cohorts to engage with technologies for study. The findings presented in this paper demonstrate that even cohorts with an overwhelmingly positive outlook towards technologies, high levels of connectedness, and high rates of device ownership, may require guidance in the use of technologies for study. This guidance is best provided through the flexible delivery of content and explicit instruction in the use of technologies for learning and university systems.

\section{Acknowledgement}

The author would like to thank her colleagues, Bronwyn Mathieson and Sharon Bryan from the JCU library for their contributions to the data collection and broader project on which this paper is based.

\section{References}

Adams Becker, S., Cummins, M., Davis, A., Freeman, A., Hall Giesinger, C., \& Ananthanarayanan, V. (2017). NMC Horizon Report: 2017 Higher Education Edition. Retrieved from https://www.nmc.org/publication/nmc-horizonreport-2017-higher-education-edition/

Australian Media \& Communications Authority [ACMA]. (2016). Communications report 2015-16. Retrieved from https://www.acma.gov.au/-/media/Researchand-Analysis/Report/pdf/ACMA-Communicationsreport-2015-16-pdf.pdf?la=en

Boyle, S., \& Abdullah, A. (2015). Factors influencing engagement with higher education pathway programs. The Journal of Developing Areas, 49(5), 169-182. doi: 10.1353/jda.2015.0057

Dahlstrom, E., \& Bichsel, J. (2014). ECAR Study of Undergraduate Students and Information Technology, 2014: Research report. Retrieved from http://www.educause.edu/ecar

Dahlstrom, E., Brooks, D. C., Grajek, S., \& Reeves, J. (2015). ECAR study of students and information technology, 2015. Louisville, KY: ECAR.

Davis, S., Connolly, A., \& Linfield, E. (2009). Lecture capture: Making the most of face-to-face learning. Engineering 
Education, 4(2), 4-13. doi: 10.11120/ened.2009.04020004

Herrington, J., Reeves, T.C., and Oliver, R. (2010) A Guide to Authentic e-Learning. Routledge, New York.

Jisc. (2011) ALT: Developing digital literacies, Retrieved from

http://www.webarchive.org.uk/wayback/archive/2 014061400244/http://www.jisc.ac.uk/whatwedo/p rogrammes/elearning/developingdigitalliteracies/al t.aspx.

Jisc. (2012). Learning in a digital age: Extending higher education opportunities for lifelong learning. Retrieved from www.jisc.ac.uk/digilifelong

Jisc. (2014). Quick guide - Developing students; digital literacy. Retrieved from http://digitalcapability.jiscinvolve.org/wp/files/201 4/09/IISC REPORT Digital Literacies 280714 PRIN T.pdf

Jisc. (2015). Digital capabilities: The 6 elements defined. Retrieved from http://digitalcapability.jiscinvolve.org/wp/files/201 5/06/1.-Digital-capabilities-6-elements.pdf

Johnson, L., Becker, S.A. \& Hall, C. (2015). 2015 NMC Technology Outlook for Australian Tertiary Education: A Horizon Project Regional Report. Retrieved from https://www.nmc.org/publication/2015-nmctechnology-outlook-2015-australian-tertiaryeducation/

Kennedy, G., Dalgarmo, B., Bennett, S., Gray, K., Judd, T. Waycott, J., ... Krause, K-L. (2009). Educating the Net generation: A handbook of findings for practice and policy. Australian Learning and Teaching Council. Retrieved

from https://web.archive.org/web/20151011044412/htt p://netgen.unimelb.edu.au/outcomes/index.html

MacPhee, D., Farro, S., \& Canetto, S. (2013). Academic SelfEfficacy and performance of underrepresented STEM majors: Gender, ethnic, and social class patterns. Analyses of Social Issues and Public Policy, 13(1), 347369. doi: 10.1111/asap.12033

Owens, J., \& Lilly, F. (2017). The influence of academic discipline, race, and gender on web-use skills among graduate-level students. Journal of Computing in Higher Education, 29(2), 286-308. doi: $10.1007 / \mathrm{s} 12528-017-9137-1$

Pitman, T., Trinidad, S., Devlin, M., Harvey, A., Brett, M., \& McKay, J. (2016). Pathways to higher education: The efficacy of enabling and sub-bachelor pathways for disadvantaged students. Retrieved from https://www.ncsehe.edu.au/publications/pathways -to-higher-education-the-efficacy-of-enabling-andsub-bachelor-pathways-for-disadvantagedstudents/
Rocchino, G., Dever, B., Telesford, A., \& Fletcher, K. (2017). Internalizing and externalizing in adolescence: The roles of academic self-efficacy and gender. Psychology in the Schools, 54(9), 905-917. doi: $10.1002 /$ pits. 22045

Roche, T. (2017). Assessing the role of digital literacy in English for Academic Purposes university pathway programs. Journal of Academic Language \& Learning, 11(1), A71-A87. Retrieved from http://journal.aall.org.au/index.php/jall/issue/view $\not 24$

Schimer, J., Yabsley, B., Mylek, M., \& Peel, D. (2016). Wellbeing, resilience and liveability in rural and regional Australia: The 2015 regional wellbeing survey. Retrieved from https://www.canberra.edu.au/research/facultyresearch-centres/ceraph/regionalwellbeing/survey-results/2015/RWS2015 WebPart-1.pdf

Strauss, A., \& Corbin, J. (1990). Basics of qualitative research: Grounded Theory procedures and techniques. Newbury Park: Sage.

Wecker, C. Kohnlet, C., \& Fischer, F. (2007). Computer literacy and inquiry learning: when geeks learn less. Journal of Computer Assisted Learning, 23(2), 133 144. doi: $10.1111 /$ j.1365-2729.2006.00218

White, B. (2009). Analysis of students' downloading of online audio lecture recordings in a large biology lecture course. Journal of College Science Teaching, 38(3), 23-27. Retrieved from http://www.jstor.org/stable/42993572

Yang, D., Catterall, J., \& Davis, J. (2013). Supporting new students from vocational education and training: Finding a reusable solution to address recurring difficulties in eLearning. Australasian Journal of Educational Technology, 29(5), 640 - 650. https://doi.org/10.14742/ajet.196

Yeung, A., Raju, S., \& Sharma, M. (2016). Online lecture recordings and lecture attendance: Investigating student preferences in a large first year psychology course. Journal of Learning Design, 9(1). 55-71. Retrieved from https://www.jld.edu.au/index-3.html 